\title{
Kahoot como estratégia lúdica no ensino-aprendizagem da Biologia Celular
}

\author{
Kahoot as a ludic strategy in the teaching learning of Cellular Biology \\ Kahoot como estrategia lúdica en la enseñanza del aprendizaje de Biología Celular
}

Recebido: 04/08/2021 | Revisado: 10/08/2021 | Aceito: 15/09/2021 | Publicado: 16/09/2021

\author{
Marcia Mourão Ramos Azevedo \\ ORCID: https://orcid.org/0000-0001-6894-0670 \\ Universidade Federal do Oeste do Pará, Brasil \\ E-mail: marcia.azevedo@ufopa.edu.br \\ Dayse Drielly Souza Santana Vieira \\ ORCID: https://orcid.org/0000-0002-2810-4317 \\ Universidade Federal do Oeste do Pará, Brasil \\ E-mail: dayse.vieira@ufopa.edu.br \\ Adriane Xavier Hager \\ ORCID: https://orcid.org/0000-0002-5270-9391 \\ Comissão Pastoral da Terra - CPT- PA, Brasil \\ E-mail: adrianehager@yahoo.com.br \\ Jonathan Correa Vieira \\ ORCID: https://orcid.org/0000-0001-8997-6277 \\ Universidade Federal do Oeste do Pará, Brasil \\ E-mail: vieirajonathan21@gmail.com \\ Andreysse Castro Vieira \\ ORCID: https://orcid.org/0000-0002-8311-8084 \\ Universidade Federal do Oeste do Pará, Brasil \\ E-mail: andreysse.vieira@gmail.com \\ Emilly Thaís Feitosa Sousa \\ ORCID: https://orcid.org/0000-0002-9187-8841 \\ Universidade Federal do Oeste do Pará, Brasil \\ E-mail: emillythais20@hotmail.com \\ Leidiane Andrade Vieira \\ ORCID: https://orcid.org/0000-0003-2268-5007 \\ Universidade Federal do Oeste do Pará, Brasil \\ E-mail: leidy4c_andrade@hotmail.com \\ Rômulo Jorge Batista Pereira \\ ORCID: https://orcid.org/0000-0002-0555-4809 \\ Universidade Federal do Oeste do Pará, Brasil \\ E-mail: romulo.jorge55@gmail.com
}

\begin{abstract}
Resumo
O ensino da Biologia Celular tem grande importância, pois compreende os processos biológicos básicos que participam da composição, formação e do funcionamento dos seres vivos. Dessa forma, torna-se primordial que o professor desenvolva alternativas pedagógicas que facilitem o processo de ensino-aprendizagem. Destaca-se, assim, o uso de metodologias ativas baseadas na utilização de Tecnologias da Informação e comunicação (TICs), despertando o interesse e promovendo a mudança de comportamento do indivíduo, tornando-os os principais protagonistas de seu processo de aprendizagem. Dessa forma, o presente trabalho objetivou analisar a aplicabilidade de um quiz, na plataforma Kahoot, como ferramenta avaliativa na disciplina de Biologia Celular. Para a aplicação do Quiz na plataforma Kahoot, foi utilizado o laboratório de informática do CJUR/UFOPA, com 25 alunos do curso de Agronomia. O resultado obtido mostra uma porcentagem maior que $50 \%$ de acertos em todas as equipes, demonstrando assim que os discentes se empenharam e se envolveram com a atividade proposta. Confirmando que as metodologias ativas contribuem com o maior engajamento e interesse, promovendo o comprometimento no processo ensino-aprendizagem, facilitando o aprendizado.
\end{abstract}

Palavras-chave: Ensino Biologia Celular; Metodologia Ativa; Kahoot.

\begin{abstract}
The teaching of Cell Biology is of great importance, as it comprises the basic biological processes that participate in the composition, formation and functioning of living beings. Thus, it is essential that the teacher develops pedagogical alternatives that facilitate the teaching-learning process. Thus, the use of active methodologies based on the use of Information and Communication Technologies (ICTs) stands out, arousing interest and promoting change in the individual's behavior, making them the main protagonists of their learning process. Thus, the present study aimed to analyze the applicability of a quiz, on the Kahoot platform, as an evaluative tool in the discipline of Cell Biology. For the application of the Quiz on the Kahoot platform, the CJUR / UFOPA computer lab was used, with 25 students from
\end{abstract}


the Agronomy course. The result obtained shows us a percentage greater than $50 \%$ of correct answers in all the teams, thus demonstrating that the students were committed and involved with the proposed activity. Confirming that active methodologies contribute to greater engagement and interest, promoting commitment in the teaching-learning process, facilitating learning.

Keywords: Teaching of Cell Biology; Active Methodology; Kahoot.

\section{Resumen}

La enseñanza de la Biología Celular es de gran importancia, ya que comprende los procesos biológicos básicos que participan en la composición, formación y funcionamiento de los seres vivos. Por ello, es fundamental que el docente desarrolle alternativas pedagógicas que faciliten el proceso de enseñanza-aprendizaje. Así, se destaca el uso de metodologías activas basadas en el uso de las Tecnologías de la Información y la Comunicación (TIC), que despiertan interés y promueven cambios en el comportamiento del individuo, convirtiéndolo en el principal protagonista de su proceso de aprendizaje. Así, este estudio tuvo como objetivo analizar la aplicabilidad de un cuestionario, en la plataforma Kahoot, como herramienta evaluativa en la disciplina de Biología Celular. Para aplicar el Quiz en la plataforma Kahoot se utilizó el laboratorio de computación CJUR / UFOPA, con 25 alumnos del curso de Agronomía. El resultado obtenido muestra un porcentaje superior al 50\% de aciertos en todos los equipos, demostrando así que los alumnos estaban comprometidos e involucrados en la actividad propuesta. Confirmando que las metodologías activas contribuyen a un mayor compromiso e interés, promoviendo el compromiso en el proceso de enseñanza-aprendizaje, facilitando el aprendizaje.

Palabras clave: Enseñanza de Biología Celular; Metodología Activa; Kahoot.

\section{Introdução}

Os modelos pedagógicos convencionais, em que o professor é o detentor de todo o conhecimento e as aulas são expositivas, tem se tornado atualmente um impasse tanto na assimilação do conteúdo por parte do aluno, quanto para o professor em promover a participação dos alunos durante a aula.

Sendo a Biologia Celular a base para a compreensão dos processos orgânicos básicos presentes desde a composição até o funcionamento dos seres vivos e suas relações com o ambiente (Hermel, 2015; Vigario \& Cicillini, 2019), é uma disciplina "chave", para o entendimento dos fenômenos biológicos. Estando, portanto, presente nos currículos da educação básica e de diversos cursos no ensino superior. Porém, seu ensino se dá de forma fragmentada e costuma privilegiar a nomenclatura das estruturas e os fenômenos celulares ao invés de seus significados e da sua contextualização (Hermel, 2015).

Desta forma, além do uso de livros didáticos e de aulas expositivas, são necessárias alternativas pedagógicas que facilitem o processo de ensino-aprendizagem e desperte o interesse dos alunos para o estudo desta ciência. A ludicidade, por exemplo, por seu caráter motivacional, dinâmico e construtivo, pode ser utilizada, associada à metodologia tradicional, constituindo em apoio eficaz ao trabalho do professor (Pereira, Aguiar, Sousa, Hager \& Azevedo, 2018; Pereira, Azevedo, Sousa \& Hager, 2020). Nos dias de hoje, os alunos crescem informatizados, logo se torna importante para a educação que as Tecnologias da Informação e Comunicação - TIC's, sejam utilizadas como uma alternativa lúdica imprescindível para o processo de ensino-aprendizagem. Estando em constante crescimento, a utilização de TICs na educação, por se tratar de recursos tecnológicos de geração e uso da informação, de forma rápida e atualizada, promove aos alunos motivação, participação, desenvolvimento cognitivo e emocional (Carvalho \& Carvalho, 2017; Nascimento \& Trompieri Filho, 2004), importantes, portanto, para a construção individual e coletiva do conhecimento nas mais diversas áreas, incluindo as ciências biológicas.

A aplicação de tecnologia foi comprovada como um meio de fomento, promoção e reforço da aprendizagem através do emprego de tecnologias como smartphones, tablets e computadores, proporcionando o engajamento e participação ativa dos alunos em salas de aula (Tan Ai Lin, Ganapathy \& Kaur, 2018).

O processo de aprendizagem demanda de metodologias capazes de promover uma educação de qualidade aos alunos, gerando-lhes saber, interesse, motivação e propiciando a assimilação dos conteúdos ministrados pelo mediador (Pinheiro Filho, 2020). Com base no pressuposto, existem várias alternativas metodológicas, incluindo os jogos, que são utilizados como um 
meio de transformar a linguagem científica complexa em um objeto atrativo e interativo, facilitando a compreensão pelo público alvo (Antunes et al., 2009).

No entanto, os jogos podem possuir duas funções: apenas com intuito de entreter ou visando ensinar, sendo denominados de educativos. Quando se trabalha com jogos lúdicos em sala de aula, é necessário saber agregar as duas funções a este material, sendo de suma importância a função educativa para ele, criando um ambiente de saber e ludicidade (Ramos, Santos \& Laburú, 2017). Nos dias atuais, os jogos digitais propõem um sistema de desafios e situações-problema que apresentam feedback construtivo e imediato para o usuário, uma característica desse sistema é a avaliação de desempenho por parte do discente, sendo de suma importância para o processo de aprendizagem, possibilitando verificar os acertos e erros do conteúdo abordado, gerando assim um retorno rápido para a correção e fixação do conhecimento adquirido (Kessler et al., 2010).

Os alunos ingressantes nas universidades são aqueles conhecidos como a "geração digital" por normalmente apresentarem facilidades em utilizar tecnologias (Howe \& Strauss, 2000). Sendo sujeitos ativos na construção de seu conhecimento, e diante deste contexto das tecnologias digitais, observa-se uma possibilidade de associar esse conhecimento tecnológico que os alunos já possuem com metodologias pedagógicas digitais, tal como o Kahoot, possibilitando uma aula lúdica, onde os mesmos se divertem aprendendo.

O Kahoot é um jogo digital que pode ser utilizado como ferramenta pedagógica, no intuito de facilitar a compreensão dos alunos combinando educação e tecnologia (Monteiro, Rodrigues \& Pinheiro, 2019). Trata-se de uma plataforma online que está disponível na internet gratuitamente (https://kahoot.com/), proporciona o e-Learning através da criação de atividades educativas e gamificadas para a dinamização de questionários contendo questões de múltipla escolha, podendo ser adotado em ambientes diversos (Bottentuit Junior, 2017). Além disso, é considerada uma ferramenta de jogos de ensino comercial, que permite ao docente a adequação a diferentes conteúdos e disciplinas (Ribeiro, Silva Junior, Frasson, Pilatti \& Silva, 2015). A plataforma oferece alguns tipos de modo de jogabilidade sendo o Quiz, onde há a utilização de um questionário com questões objetivas e temporizada, Jumble, onde está vinculado um sistema de quebra-cabeça, Discussion e Survey onde é apresentado em forma de enquete para o usuário, todos os modos de jogo são criados pelo docente, sendo os modos mais empregados o Quiz e Jamble (Bottentuit Junior, 2017).

A avaliação adotada no jogo pode ser apresentada de duas formas: somativa, quando o resultado é gerado ao fim do jogo; e a formativa, a qual visa o sistema de feedback, ao longo do percurso do quiz, o sistema vai gerando uma resposta imediata de pontuação, caso esteja correta ou errada, com correção do problema (Ismail \& Mohammad, 2017). O modo quiz gera um feedback imediato, permitindo ao usuário acompanhar seu progresso no jogo. Além disso, à medida que o jogo avança, é possível verificar motivação, engajamento, esforço para alcançar os objetivos, foco, confiança, interesse no assunto abordado na atividade e a correção de seus conhecimentos, facilitando a aprendizagem e fixação do conteúdo tornando as avaliações mais eficazes e produtivas para professor e aluno (Tan Ai Lin et al., 2018).

O presente trabalho objetivou analisar a aplicabilidade de um quiz, na plataforma Kahoot, como ferramenta avaliativa na disciplina de Biologia Celular.

\section{Metodologia}

A atividade foi realizada no primeiro semestre de 2019, na cidade de Juruti, no Campus Universitário de Juruti da Universidade Federal do Oeste do Pará (CJUR/UFOPA), com os discentes do curso de Bacharelado em Agronomia.

A disciplina de Biologia Celular continha 30 (trinta) discentes matriculados, no entanto, apenas 25 (vinte e cinco) participaram da atividade proposta. O Quiz de Biologia Celular, aplicado por meio da plataforma Kahoot, foi utilizado para avaliar a aprendizagem dos alunos. Além da Professora, duas monitoras estiveram envolvidas de forma ativa na organização e 
no desenvolvimento das atividades.

Após ministrar os conteúdos, os discentes foram divididos em quatro equipes, compostas por, cerca de, 7 (sete) membros, sendo que no dia da avaliação alguns membros de três das equipes faltaram. Para identificação, foi sorteada uma cor para cada uma das equipes, sendo elas amarela, azul, verde e vermelha. Posteriormente, foram repassadas algumas informações e instruções sobre a plataforma e agendada uma aula para o devido conhecimento e manuseio da mesma, antes da data da avaliação.

A avaliação foi realizada na plataforma Kahoot (kahoot.com), onde foram elaboradas e cadastradas 32 (trinta e duas) questões pela docente, relacionadas aos seguintes conteúdos: Estrutura organizacional da célula procarionte e eucarionte; Organelas citoplasmáticas; Dogma Central da Biologia; Replicação do DNA, Transcrição do DNA Síntese proteica (tradução) e Divisão Celular.

Para a realização desta atividade utilizou-se o laboratório de informática do CJUR, que continha 22 (vinte e dois) computadores, os três alunos restantes, utilizaram equipamentos celulares. O Quiz foi jogado no modo "Player", onde as respostas foram dadas individualmente. A pontuação de cada equipe foi obtida pela média do Total Score dos membros da equipe. Após cada pergunta, principalmente nas que ocorreram o maior número de respostas incorretas, era realizado um debate sobre o assunto.

A saída dos dados da plataforma Kahoot, em planilha de Excel, foram utilizados para a construção das tabelas e do Box Plot.

\section{Resultados e Discussão}

A introdução de novas tecnologias no processo de ensino aprendizagem pelos professores tem sido utilizada como metodologia para manter a motivação e o engajamento dos estudantes (Libâneo, 2013; Morais, 2017).

A utilização do game Kahoot na disciplina de Biologia Celular para o curso de Bacharelado em Agronomia do Campus Universitário de Juruti possibilitou trabalhar melhor os conteúdos abordados em sala, de modo a resgatar conceitos, diversificar o modelo de ensino e também engajar mais os discentes nos trabalhos em grupos e interação com a turma. Tais fatos também foram relatados nos trabalhos desenvolvidos por Fardo (2013) e Prá, Freitas e Amico (2017), em que a aplicação do game serviu para aumentar o interesse e motivar os discentes, potencializando o processo de ensino-aprendizagem.

Avaliando o jogo Quiz aplicado ao ensino de Biologia Celular, Oliveira, Antunes, Farias, Vigário e Sabóia-Morais (2012) também verificaram que o jogo, quando utilizado como ferramenta pedagógica, desenvolve a autonomia, a integração, a participação e a promoção de aprendizagem significativa.

Na Figura 1 pode-se observar os discentes envolvidos na aplicação do Kahoot na disciplina de Biologia Celular, corroborando com os resultados dos trabalhos supracitados.

Nessa perspectiva, estudo realizado por Bottentuit Junior (2017) ratifica os benefícios da utilização do aplicativo Kahoot na educação ao afirmar que o seu uso aumenta o interesse do aluno para a aprendizagem e melhora as práticas pedagógicas. No entanto, segundo o mesmo autor, o sucesso do uso da tecnologia no processo de ensino depende do bom planejamento das atividades a serem realizadas em que as tecnologias devem estar alinhadas aos objetivos educacionais. 
Figura 1: Aplicação do Kahoot no laboratório de ensino durante a aula da disciplina de Biologia Celular do curso de Bacharelado em Agronomia do Campus Universitário de Juruti.

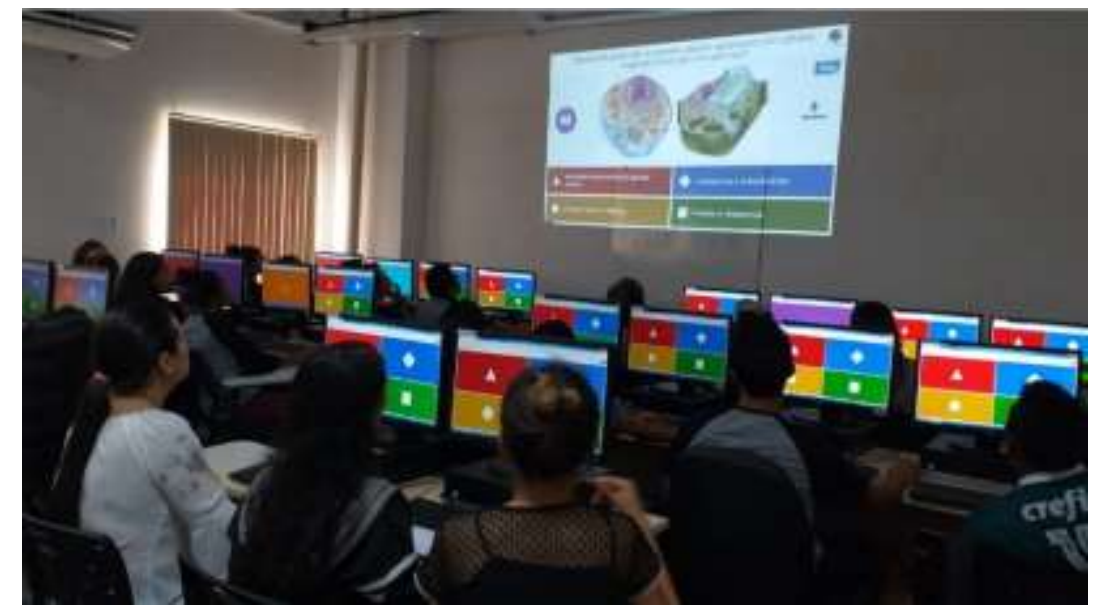

Fonte: Elaborado pelos autores.

Na Tabela 1 são apresentadas as porcentagens de acertos e erros relacionados às temáticas abordadas nas 32 questões realizadas no Kahoot, sendo estas elencadas da seguinte forma: i) DNA e RNA - 11 questões; ii) Divisão celular - 10 questões; iii) Células e Organelas - 6 questões; iv) Dogma Central da Biologia - 5 questões. Foi observado que o maior número de acertos foi obtido na temática Células e Organelas (79,33\%), seguindo por Divisão Celular (66,80\%), DNA e RNA $(53,82 \%)$ e por fim, Dogma Central da Biologia (42,40\%). Esses resultados confirmam o trabalho de Wood-Robinson, Lewis e Leach (2000), que argumentam existir diversos estudos que demonstram que a Genética é um tema difícil de assimilar. O grau de dificuldade aumenta quando falamos de Dogma Central da Biologia, pois compreende conceitos abstratos como: estruturas moleculares do DNA, processos de duplicação, transcrição e tradução. Dessa forma, os resultados do presente trabalho revelam que os alunos precisavam estudar mais os conteúdos, Dogma Central da Biologia e DNA e RNA para melhorar o desempenho. Corroborando com Silva (2018) ao afirmar que o Kahoot é uma importante ferramenta de acompanhamento dos alunos ao longo do processo de aprendizagem.

Tabela 1: Apresentação das porcentagens de acertos e erros relacionados à temática e número de questões aplicadas.

\begin{tabular}{|c|c|c|c|c|c|c|}
\hline \multirow{2}{*}{ Temática } & \multirow{2}{*}{$\begin{array}{c}\mathrm{N}^{\circ} \text { de } \\
\text { questões }\end{array}$} & \multirow{2}{*}{$\begin{array}{c}\mathrm{N}^{\mathrm{o}} \text { de } \\
\text { acertos }\end{array}$} & \multirow{2}{*}{$\mathrm{N}^{\mathrm{o}}$ de erros } & \multirow{2}{*}{$\begin{array}{c}\mathrm{N}^{\mathrm{o}} \mathrm{de} \\
\text { respostas }\end{array}$} & \multicolumn{2}{|c|}{ Porcentagem } \\
\hline & & & & & Acertos & Erros \\
\hline DNA e RNA & 11 & 148 & 127 & 275 & 53,82 & 46,18 \\
\hline Divisão Celular & 10 & 167 & 83 & 250 & 66,80 & 33,20 \\
\hline Células e Organelas & 6 & 119 & 31 & 150 & 79,33 & 20,67 \\
\hline Dogma Central & 5 & 53 & 72 & 125 & 42,40 & 57,60 \\
\hline Total & 32 & 487 & 313 & 800 & - & - \\
\hline
\end{tabular}

Fonte: Elaborado pelos autores.

Ressalta-se que nas questões onde ocorreram maior número de respostas incorretas foram realizados debates sobre o assunto. Estudos como de Sousa (2019) corroboram essa prática em que no decorrer da aplicação do Kahoot, haviam debates sobre as perguntas/respostas, permitindo aos alunos sanar as suas dúvidas logo após cada pergunta.

Já Silva (2018) verificou que o processo de aprendizagem diferiu entre os discentes, desta forma, nas questões que o 
percentual de acerto foi menor que $60 \%$ o assunto foi trabalhado novamente, aprimorando o processo de aprendizagem.

É importante destacar que a utilização de metodologias ativas proporciona que aos alunos se tornem agentes ativos na construção do conhecimento, promovendo o comprometimento no processo ensino-aprendizagem, além de fomentar o desenvolvimento de trabalhos em grupo e a partilha de conhecimentos (Silva, 2018).

Na Tabela 2 estão apresentados o desempenho das 4 equipes envolvidas no game do Kahoot, sendo elas: i) Vermelha - 7 integrantes; ii) Amarela - 6 integrantes; iii) Verde - 7 integrantes; e iv) Azul - 5 integrantes. A equipe que apresentou a maior média de respostas corretas foi à vermelha com 23,4, seguida pela azul $(19,4)$, amarela $(18,5)$ e verde $(16,4)$. É importante ressaltar que as médias foram calculadas com base no número de integrantes de cada equipe. Observou-se, ainda, variação no número de respostas obtidas ( $\mathrm{N}^{\circ}$ de respostas - máximo e mínimo). Nas equipes tiveram integrantes que responderam todas as questões propostas, sendo que na vermelha, amarela e azul, tiveram integrantes que responderam somente 28 questões, enquanto na verde, o mínimo foi de 29 questões respondidas. No presente estudo, considerou-se as respostas deixadas em branco como incorretas. Contudo, de modo geral, os discentes se envolveram na atividade proposta e apresentaram, na média geral, resultado superior a $60 \%$ de respostas corretas, valores próximos aos obtidos por Alves \& Roza (2018), de 56,02\% e de 58,63\%, ao utilizarem o Kahoot com o objetivo de revisar os conteúdos da avaliação na disciplina de Gerenciamento de Projetos para dois cursos superiores. Segundo o professor, os resultados da revisão foram regulares, que os alunos deveriam estudar mais determinados conteúdos para melhorar o desempenho na avaliação final.

Tabela 2: Desempenho médio das equipes que participaram da aplicação do game Kahoot.

\begin{tabular}{|c|c|c|c|c|c|c|c|c|}
\hline \multirow{2}{*}{ Equipe } & \multirow{2}{*}{$\begin{array}{c}\mathrm{N}^{\mathrm{o}} \mathrm{de} \\
\text { jogadores }\end{array}$} & \multicolumn{2}{|c|}{ Respostas (média) } & \multicolumn{2}{|c|}{$\mathrm{N}^{\circ}$ de respostas } & \multirow{2}{*}{$\begin{array}{c}\text { Placar final } \\
\text { (média) }\end{array}$} & \multicolumn{2}{|c|}{ Porcentagem } \\
\hline & & Corretas & Incorretas & Máximo & Mínimo & & Corretas & Incorretas \\
\hline Vermelha & 7 & 23,4 & 8,6 & 32 & 28 & 22935,9 & 73,21 & 26,79 \\
\hline Amarela & 6 & 18,5 & 13,5 & 32 & 28 & 17077,0 & 57,81 & 42,19 \\
\hline Verde & 7 & 16,4 & 15,6 & 32 & 29 & 14846,0 & 51,34 & 48,66 \\
\hline Azul & 5 & 19,4 & 12,6 & 32 & 28 & 17445,6 & 60,63 & 39,38 \\
\hline Média Geral & 6,25 & 19,4 & 12,6 & - & - & 18076,1 & 60,75 & 39,25 \\
\hline
\end{tabular}

Fonte: Elaborado pelos autores.

O placar final com a pontuação segundo o Kahoot, bem como a porcentagem de respostas corretas, apresentou o seguinte ranque: $1^{\circ}$ Lugar - Vermelha, com 22935,9 pontos e 73\% de acertos; $2^{\circ}$ Lugar - Azul, com 17445,6 pontos e $61 \%$ de acertos; $3^{\circ}$ Lugar - Amarela, com 17077 pontos e 58\% de acertos; e $4^{\circ}$ Lugar - Verde, com 14846 pontos e 51\% de acertos. É válido ressaltar que, independentemente da equipe vencedora, foi obtida uma porcentagem maior que $50 \%$ de acertos em todas as equipes, demonstrando assim que os discentes se empenharam e se envolveram com a atividade proposta. $\mathrm{O}$ resultado do presente estudo foi diferente do encontrado por Sousa (2019), que avaliando os conhecimentos prévios de matemática com alunos do ensino médio, encontrou menos de 30\% de acertos nas questões. As divergências observadas nos trabalhos em questão, podem ser decorrentes tanto do público alvo diferente, como também das temáticas abordadas.

Na Figura 2 é apresentado um gráfico box plot com a variação das respostas corretas dentro dos grupos, levando em consideração o número de participantes nas equipes mostrados na Tabela 2. Pode-se observar que o grupo com maior homogeneidade de respostas corretas foi a equipe vermelha, visto que a variação entre o primeiro e terceiro quartil, correspondente a 50\% das respostas, foi a menor entre os grupos. Já a maior heterogeneidade foi observada na equipe verde, pois apresentou maior variação entre o primeiro e terceiro quartil. Fatos este que corroboram com os dados apresentados na Tabela 2 , onde a equipe vermelha obteve a maior pontuação no placar final da atividade, e a equipe verde, a menor. As equipes 
amarela e azul apresentaram variação média, e obtiveram placares intermediários entre as equipes vermelha e verde. É importante ressaltar que o fato observado na Figura 2 também pode ter ocorrido devido a inexistência de resposta de alguns participantes da equipe nas questões, aumentando a variabilidade dentro do grupo.

Figura 2: Gráfico Box Plot apresentando a variação das respostas corretas dos integrantes dentro de cada equipe conforme os quartis.

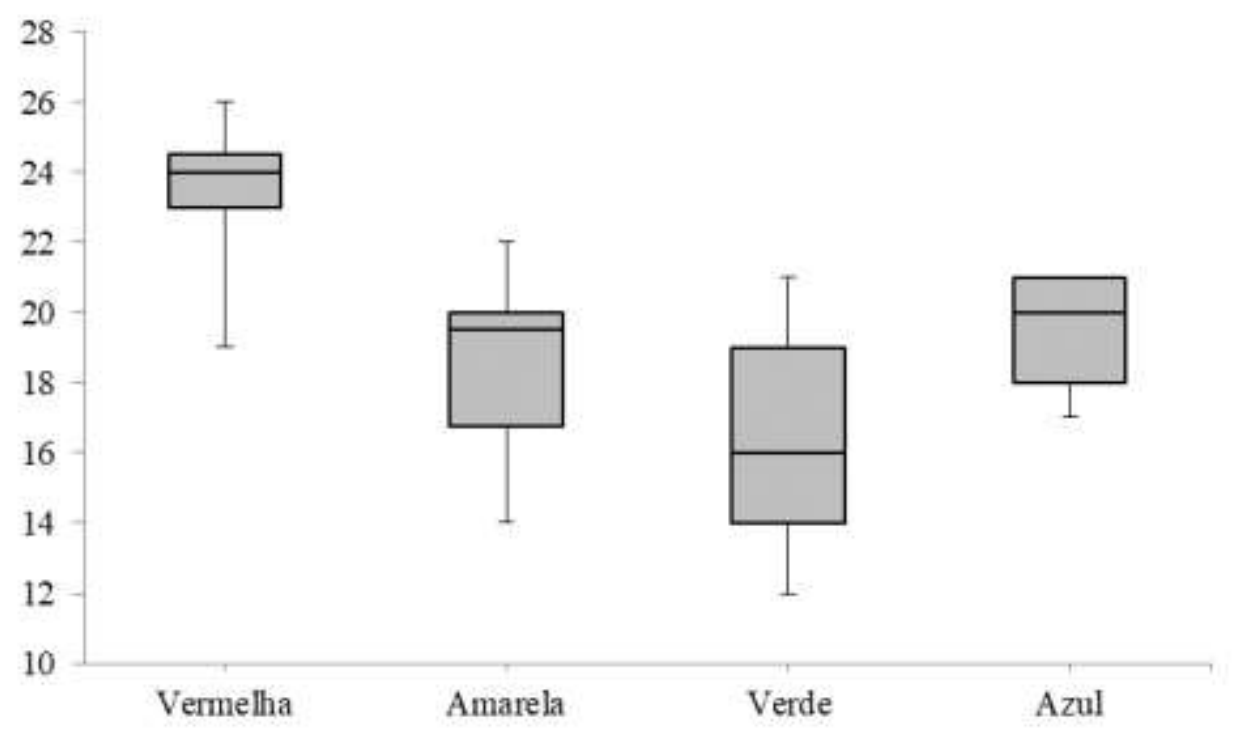

Fonte: Elaborado pelos autores.

A criação de um ambiente favorável à aprendizagem pode propiciar a participação ativa dos estudantes, mas para isso é indispensável o planejamento da atividade, verificando as ferramentas disponíveis, além de fomentar o envolvimento dos discentes. No presente trabalho, observou-se que a ideia de gamificação foi capaz de envolver os discentes, corroborando com os resultados dos trabalhos de Costa, Dantas Filho e Moita (2017) e Sande \& Sande (2018), que tiveram conclusões semelhantes. Existem inúmeros benefícios para o processo ensino-aprendizagem a integração da tecnologia, educação e gamificação (Prá et al., 2017). Contudo, é importante lembrar, que na atual conjuntura, não são todos os brasileiros que possuem acesso à internet e computador/smartfone, além de não dominarem a utilização dessas tecnologias, para que tal integração seja generalizada.

\section{Conclusão}

O desenvolvimento do presente trabalho, utilizando metodologia ativa através da gamificação, corroborou com os resultados de outros trabalhos, destacando a ideia da gamificação no envolvimento dos discentes para o processo de aprendizagem, tornando-os sujeitos ativos na construção do seu conhecimento.

Observou-se que, de modo geral, os discentes tiveram grande envolvimento na atividade proposta e apresentaram resultados superiores a 50\% de acertos, por grupo, na resolução das questões do quiz/kahoot, demonstrando a importância da aplicação de metodologias diferenciadas, para a criação de ambiente favorável ao aprendizado, proporcionando uma participação ativa dos estudantes e contribuindo para o desenvolvimento do amadurecimento acadêmico dos discentes, assim corroborando com o processo de construção do conhecimento coletivo.

A aprendizagem com enfoque puramente tradicional, normalmente, ocorre de forma fragmentada, precisando agregar teorias e práticas diferenciadas, e principalmente incluindo metodologias diferenciadas, como suporte facilitador do processo 
de ensino e de aprendizagem, como desenvolvido neste trabalho com o uso da gamificação.

Portanto, com base nos resultados obtidos neste trabalho fica clara a importância da aplicação de metodologias ativas para despertar nos alunos o interesse e o envolvimento na construção de seus conhecimentos, nesse sentido, considera-se que a Universidade tem o papel primordial na difusão do conhecimento e das práticas de uso de novas metodologias educacionais.

Cabe aqui destacar, a dificuldade de acesso por grande parte dos brasileiros, incluindo docentes e discentes nesta realidade, à Internet e a equipamentos eletrônicos (computadores, tablets, celulares...), além de também não terem o domínio dessas tecnologias. Necessita-se, portanto, de políticas de inclusão e maior e melhor acesso a tais tecnologias para que a integração entre educação, tecnologias e metodologias ativas através de gamificação, seja generalizada.

\section{Referências}

Alves, N. A., \& Roza, R. H. (2018). Gamificação no ensino de administração: o uso da plataforma Kahoot em uma disciplina de gestão de projetos. Revista Tecnologias na Educação, 10(25), 1-9. http://tecedu.pro.br/wp-content/uploads/2018/07/Rel4-vol25-Julho2018.pdf

Antunes, A. M., Morais, C. M. O. de, Silva, E. F. da, Dutra, M. F., Marineli, P. F. S., Souza Filho, J., Santos, A. P. R. dos, \& Sabóia-Morais, S. M. T. (2009). A utilização de metodologias lúdicas no ensino de biologia: estudo do valor educativo de jogos em escola urbana e rural. In III Encontro Estadual de Didática $\mathrm{e} \quad$ Prática Ansino. Ánolis-GO. http://cepedgoias.com.br/edipe/IIIedipe/pdfs/2_trabalhos/gt04_fisica_quimica_biologia_ciencias/trab_gt04_a_utilizacao_de_metodologias_ludicas.pdf

Bottentuit Junior, J. B. (2017). O aplicativo Kahoot na educação: verificando os conhecimentos dos alunos em tempo real. Challenges: Aprender nas Nuvens, Learning in the Clouds. 1587-1602. http://fatecead.com.br/ma/artigo01.pdf

Carvalho, N. B., \& Carvalho, A. C. F. (2017). Uso dos Recursos Tecnológicos Atuais e sua contribuição no processo de Ensino-Aprendizagem na Escola Municipal Érico Veríssimo, Simões-PI. Revista Multidisciplinar e de Psicologia, 10(33), 112-125. https://doi.org/10.14295/idonline.v10i33.643

Costa, C. H. C., Dantas Filho, F. F., \& Moita, F. M. G. S. C. (2017). Marvinsketch e kahoot como ferramentas no ensino de isomeria. HOLOS, $33(1)$, $31-43$.

Fardo, M. L. (2013). A gamificação aplicada em ambientes de aprendizagem. Revista Renote, 11(1), 1-9.

Hermel, E. E. S. (2015). O Ensino de Biologia Celular na formação inicial de professores de Ciências e de Biologia. In I. M. S. de Farias, M. S. L. Lima, M. M. D. Cavalcante, \& J. A. M. de Sales (Orgs.), Didática e a prática de ensino na relação com a formação de professores (Livro 2, pp 1-6). EdUECE.

Howe, N., \& Strauss, W. (2000). Millenials Rising: The Next Great Generation. 1st Ed. Toronto, Canada: Random House, Inc. 415 p.

Ismail, MA-A., \& Mohammad, JA-M. (2017). Kahoot: a promising tool for formative assessment in medical education. Education in Medicine Journal. 9(2), 19-26. https://doi.org/ 10.21315/eimj2017.9.2.2

Kessler, M. C., Paula, C. G. de, Albé, M. H., Manzini, N., Barcellos, C., Carlson, R., Marcon, D., \& Kehl, C. (2010). Impulsionando a aprendizagem na Universidade por meio de Jogos Educativos Digitais. In Simpósio Brasileiro de Informática na Educação - SBIE. Rio de Janeiro. http://dx.doi.org/10.5753/cbie.sbie.2010.\%25p

Libâneo, J. C. (2013). Adeus professor, adeus professora? Novas exigências profissionais e profissão docente. São Paulo: Cortez.

Morais, S. S. R. (2017). Tecnologia e Educação. Anais... XIV EVIDOSOL e X CILTEC-Online, 6(1).

Monteiro, J. C. da S., Rodrigues, S. F. N., \& Pinheiro, S. C. B. (2019) APP-LEARNING: contribuições do Kahoot no Ensino de Jornalismo. Revista Observatório, 5(6), 305-327.

Nascimento, R. B., \& Trompieri Filho, N. (2004). Atitudes face às tecnologias da informação. Transinformação, 16(1), 33-45. http://dx.doi.org/10.1590/S0103-37862004000100003

Oliveira, M. L. de., Antunes, A. M., Faria, J. C. N. de M., Vigário, A. F., \& Sabóia-Morais, S. M. T de. (2012). O jogo Quiz aplicado ao ensino de Biologia Celular: uma abordagem lúdica para construção do conhecimento científico no espaço universitário. Interação - Revista De Ensino, Pesquisa E Extensão, 14(14), 148-168. https://doi.org/10.33836/interacao.v14i14

Pereira, R. J. B., Aguiar, A. S., Sousa, E. T. F., Hager, A. X., \& Azevedo, M. M. R. R. (2018). Avaliação de três metodologias de ensino em biologia na modalidade EJA em escolas do município de Santarém-PA. Revista Eletrônica de Educação da Faculdade Araguaia, 13(2), 1-10. http://www.faculdadearaguaia.edu.br/sipe/index.php/renefara/article/view/660/pdf_152

Pereira, R. J. B., Azevedo, M. M. R. R., Sousa, E. T. F., \& Hager, A. X. (2020). Método tradicional e estratégias lúdicas no ensino de Biologia para alunos de escola rural do município de Santarém-PA. Experiências em Ensino de Ciências, 15(2), 106-123. https://if.ufmt.br/eenci/artigos/Artigo_ID717/v15_n2_a2020.pdf

Pinheiro Filho, I. S. (2020). Educação e Tecnologia: O Uso de Recursos Inovadores no Processo de Ensino-Aprendizagem. Revista Multidisciplinar e de Psicologia. 14(51), 1008-1020. https://doi.org/10.14295/idonline.v14i51.2652 
Research, Society and Development, v. 10, n. 12, e159101219049, 2021

(CC BY 4.0) | ISSN 2525-3409 | DOI: http://dx.doi.org/10.33448/rsd-v10i12.19049

Prá, R., Freitas, T. A., \& Amico, M. R. de A. (2017). Análise da ferramenta Kahoot como facilitadora do processo de ensino aprendizagem. $22^{\circ}$ Seminário de Educação, Tecnologia e Sociedade. Núcleo de Educação On-line/ NEO; FACCAT, RS. Revista Redin, 6(1). https://seer.faccat.br/index.php/redin/article/view/644

Ramos, E.S., Santos, F. A. C., \& Laburú, C. E. (2017). Uso da Ludicidade Como Ferramenta Para o Ensino de Química Orgânica: o que pensam os alunos. ACTIO: Docência em Ciências. 2(1), 119-136. http://dx.doi.org/10.3895/actio.v2n2.6810

Ribeiro, R. J., Silva Junior, N., Frasson, A. C., Pilatti, L. A., \& Silva, S. de C. R. da. (2015). Teorias de Aprendizagem em Jogos Digitais Educacionais: um Panorama Brasileiro. Revista Novas Tecnologias na Educação. 13(1), 1-10. https://doi.org/10.22456/1679-1916.57589

Sande, D., \& Sande, D. (2018). Uso do kahoot como ferramenta de avaliação e ensino-aprendizagem no ensino de microbiologia industrial. HOLOS, 34(1), 170-179. https://www2.ifrn.edu.br/ojs/index.php/HOLOS/article/view/6300/pdf

Silva, M. C. P. da. (2018). Uso do Kahoot! Como ferramenta de avaliação e ensino-aprendizagem no ensino da membrana plasmática. Estácio Saúde, 7(2), 69 .

Sousa, M. A. de (2019). O uso da plataforma kahoot como método de ensino-aprendizagem no ensino da matemática. VI Congresso Nacional de Educação. https://editorarealize.com.br/editora/anais/conedu/2019/TRABALHO_EV127_MD1_SA19_ID3323_26092019101246.pdf

Tan Ai Lin, D., Ganapathy M., \& Kaur, M. (2018). Kahoot! It: Gamification in Higher Education. Pertanika Journal of Social Sciences \& Humanities. 26(1), 565-582.

https://www.researchgate.net/profile/Debbita_Tan/publication/320182671_Kahoot_It_Gamification_in_Higher_Education/links/5ab3757aa6fdcc1bc0c288fe/ Kahoot-It-Gamification-in-Higher-Education.pdf

Vigario, A. F., \& Cicillini, G. A. (2019). Os saberes e a trama do ensino de Biologia Celular no nível médio. Ciência \& Educação (Bauru), 25(1), 57-74. https://www.scielo.br/pdf/ciedu/v25n1/1516-7313-ciedu-25-01-0057.pdf

Wood-Robinson, C., Lewis, J., \& Leach, J. (2000). Young people's understanding of the nature of genetic information in the cells of an organism. Journal of Biological Education, 35:1, 29-36. 